\title{
Rapid Monitoring of Mercury in Air from an Organic Chemical Factory in China Using a Portable Mercury Analyzer
}

Akira Yasutake, ${ }^{1}$ Jin Ping Cheng, ${ }^{2}$ Masako Kiyono, ${ }^{3}$ Shimpei Uraguchi, ${ }^{4}$ Xiaojie Liu, ${ }^{5}$ Kyoko Miura, ${ }^{6}$ Yoshiaki Yasuda, ${ }^{1}$ and Nikolay Mashyanov ${ }^{7}$

${ }^{1}$ Kumamoto University Graduate School of Science and Technology, 2-39-1 Kurokami, Kumamoto 860-8555, Japan

${ }^{2}$ School of Environmental Science and Engineering, Shanghai Jiao Tong University, 800 Dong Chuan Road, Shanghai 200240, China

${ }^{3}$ Department of Public Health, School of Pharmaceutical Sciences, Kitasato University, 5-9-1 Shirokane, Minato-ku, Tokyo 108-8641, Japan

${ }^{4}$ Biotechnology Research Center, The University of Tokyo, Yayoi, Bunkyo-ku, Tokyo 113-8657, Japan

${ }^{5}$ National Institute for Minamata Disease, 4058-18 Hama, Minamata, Kumamoto 8670008, Japan

${ }^{6}$ Department of Environmental Sciences, Faculty of Economics, Wako University, 2160 Kanai-cho, Machida, Tokyo 195-8585, Japan

${ }^{7}$ Department of Geology, St. Petersburg State University, 7/9 Universitetskaya nab., St. Petersburg 199034, Russia

Received 26 January 2011; Accepted 20 March 2011

Academic Editor: Richard Brown

A chemical factory, using a production technology of acetaldehyde with mercury catalysis, was located southeast of Qingzhen City in Guizhou Province, China. Previous research showed heavy mercury pollution through an extensive downstream area. A current investigation of the mercury distribution in ambient air, soils, and plants suggests that mobile mercury species in soils created elevated mercury concentrations in ambient air and vegetation. Mercury concentrations of up to $600 \mathrm{ng} / \mathrm{m}^{3}$ in air over the contaminated area provided evidence of the mercury transformation to volatile $\mathrm{Hg}(0)$. Mercury analysis of soil and plant samples demonstrated that the mercury concentrations in soil with vaporized and plant-absorbable forms were higher in the southern area, which was closer to the factory. Our results suggest that air monitoring using a portable mercury analyzer can be a convenient and useful method for the rapid detection and mapping of mercury pollution in advanced field surveys.

KEYWORDS: Guizhou, mercury pollution, air, soils, vegetation 


\section{INTRODUCTION}

The valley of the Zhujia River east of Qingzhen City in Guizhou Province, China, is polluted by mercurycontaminated wastewater from the Guizhou Organic Chemical Factory (Figure 1). The acetaldehyde production technology with mercury catalysis used in the factory was similar to that involved in the pollution disaster in Minamata City, Japan. For 27 years (1971-1998), the factory in Guizhou discharged mercury with its wastewater into the Zhujia River [1]. The polluted area was considerably enlarged due to farmland irrigated by mercury-contaminated water from the river. Previously, we analyzed both total and methylmercury in soils of the Qingzhen fields and showed that the area along the river up to about $1 \mathrm{~km}$ downstream of the factory should be designated as "highly contaminated area" [2-4].

Mercury in soil interconverts between inorganic and organic species depending on physicochemical and environmental factors. Methylmercury levels in the soil samples showed a good correlation $(r=0.89)$ to total mercury levels throughout the whole Qingzhen area, irrespective of a significant difference in total mercury levels between high- and low-contamination areas [3]. Mercury interconversion in the soil is also possible between different inorganic mercury compounds and elemental mercury, and the latter can readily vaporize into air. Accordingly, the air mercury level may be used to reveal contamination levels in soils. The present data are intended to promote further research of mercury distribution in soils, vegetation, and surface air within highly contaminated industrial areas.

\section{METHODS}

Soil and vegetation sampling, along with an air survey, was carried out from 2 to 10 March 2005 in the southeastern vicinity of Qingzhen City at the area designated as "highly contaminated" [3]. A Lumex RA915+ Zeeman mercury analyzer (Lumex Ltd., Russia) was used for the air mercury survey [5, 6]. The analyzer enables direct and continuous determination of the mercury concentration in air with a response time of $1 \mathrm{~s}$. The detection limit of the instrument is $0.5 \mathrm{ng} \mathrm{Hg} / \mathrm{m}^{3}$ for an averaging time of $10 \mathrm{~s}$. Sampling points were set up along the river (see Figure 1) at $50 \mathrm{~m}$ intervals ( $10 \mathrm{~m}$ within areas where the $\mathrm{Hg}$ concentration in air exceeded $100 \mathrm{ng} / \mathrm{m}^{3}$ ).

Prior to the regular air survey, we examined the vertical mercury distribution and the effect of surface soil removal to optimize the ambient air sampling technique. The regular measurements were conducted $5 \mathrm{~cm}$ above the surface using a cylindrical chamber (Figure 2) to minimize the effects of airborne mercury transfer. The air exchange inside the chamber at a pumping rate of $15 \mathrm{~L} / \mathrm{min}$ is equal to that created by a wind speed of $0.04 \mathrm{~m} / \mathrm{s}$. Mercury concentration inside the chamber was measured continuously with a flow rate of $15 \mathrm{~L} / \mathrm{min}$ and a signal accumulation for every $10 \mathrm{~s}$, putting the mouth of an inlet tube of the analyzer at a height of $5 \mathrm{~cm}$ above the surface. The $10 \mathrm{~s}$ measurements were repeated 6 times, and the mean value for $1 \mathrm{~min}$ was calculated. The mercury concentration level in the surface air was measured both before and after removing about $5 \mathrm{~cm}$ thick layer of surface soils, and the latter were used as actual data. Then, about $5 \mathrm{~g}$ of soil from the surface at a $5 \mathrm{~cm}$ depth was taken for total mercury analysis.

Mercury analysis of the soil samples was performed according to Rodrigues et al. [7]. The soil samples were dried in a shady and aerated place at room temperature until achieving constant weight. Then the samples were ground in a carnelian mortar and sifted through a 100-mesh nylon screen plate. An aliquot of 50-100 mg of each sample was subjected to total mercury analysis using an AMA-254 mercury analyzer (Milestone, USA).

The investigated area was mostly used as paddy fields, and rape (Brassica rapa) was grown there in spring. The leaves of Brassica rapa grown close to the sampling sites where available were taken for mercury analysis. The leaf samples were washed carefully with tap water and rinsed three times using distilled water to remove soil or dust from the leaves. The samples were dried at $60^{\circ} \mathrm{C}$ for three days. Mercury analysis of the samples was conducted according to the method described by Uraguchi et al. [8]. Powdered samples (up to $100 \mathrm{mg}$ dry wt.) were digested with $2 \mathrm{~mL}$ of nitric acid in a microwave 

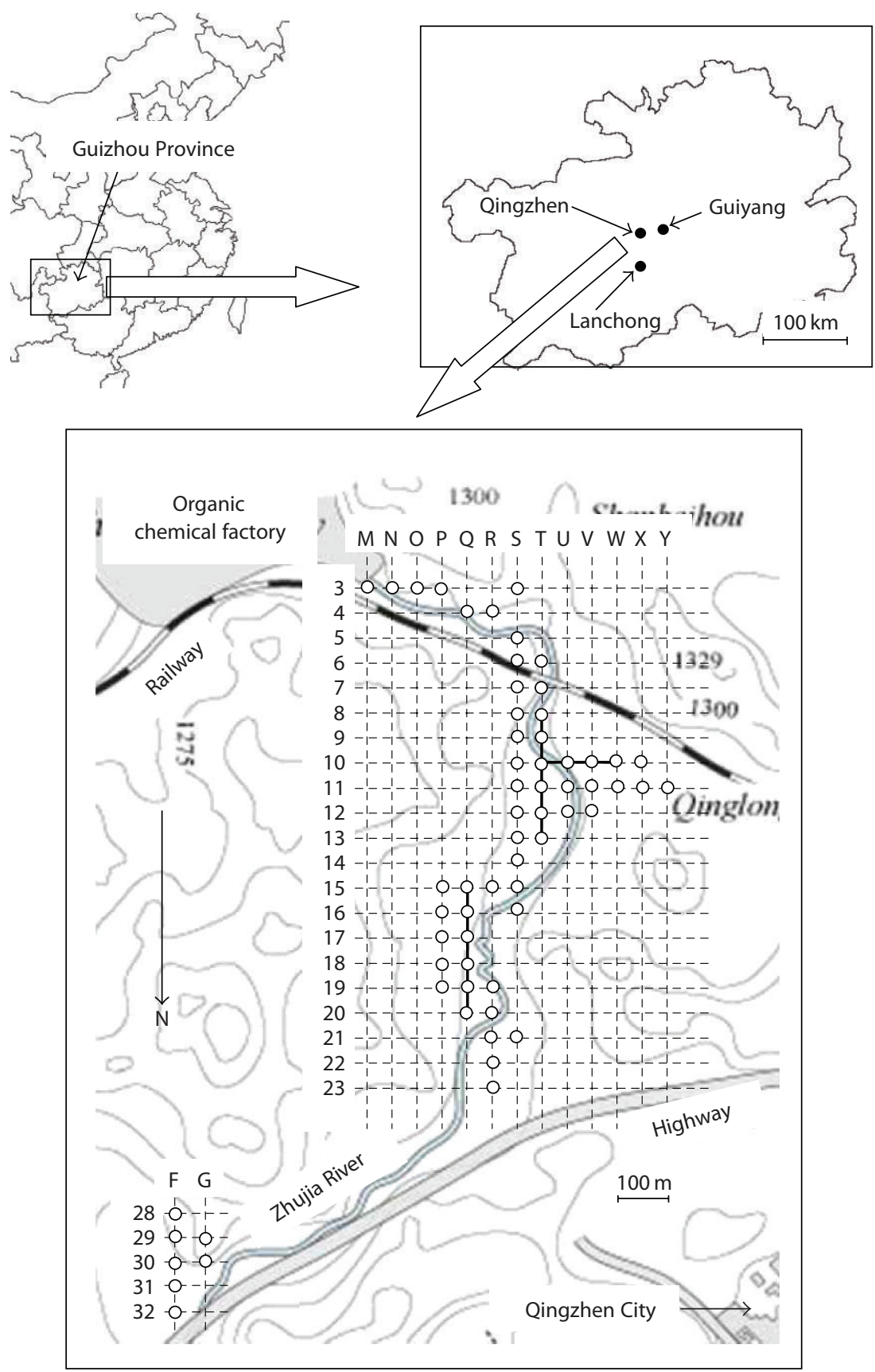

FIGURE 1: Location: map of China and investigated area.

system. After dilution and filtration, the $\mathrm{Hg}$ concentration was analyzed by cold vapor atomic absorption spectrometry (CV AAS) using a Hiranuma HG-300 spectrophotometer (Hiranuma Sangyo Co., Japan). The accuracy and validity of the analyses were assessed using standard reference material NIES no. 1 (National Institute for Environmental Studies, Japan).

To obtain background mercury concentration levels, similar samplings were carried out at 5 points within a nonpolluted rice field in Lanchong Village $60 \mathrm{~km}$ southwest of Qingzhen City. 


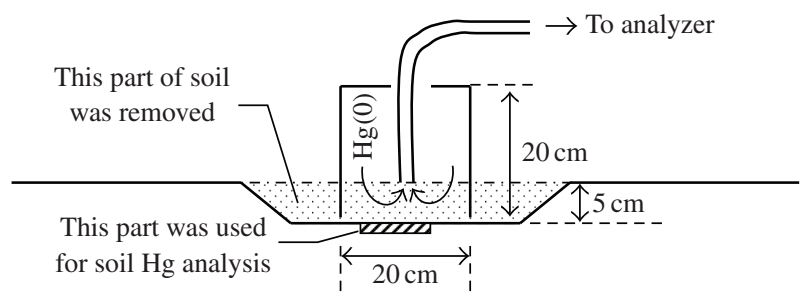

FIGURE 2: Sampling chamber for air mercury. Before air measurement, surface soil of about $5 \mathrm{~cm}$ thickness was removed, and a cylindrical chamber $(20 \mathrm{~cm}$ diameter $\times 20 \mathrm{~cm}$ height) with a sampling hole $(5 \mathrm{~cm}$ diameter) at the top was placed on the surface. After air sampling, about $5 \mathrm{~g}$ of soil was taken for mercury analysis.

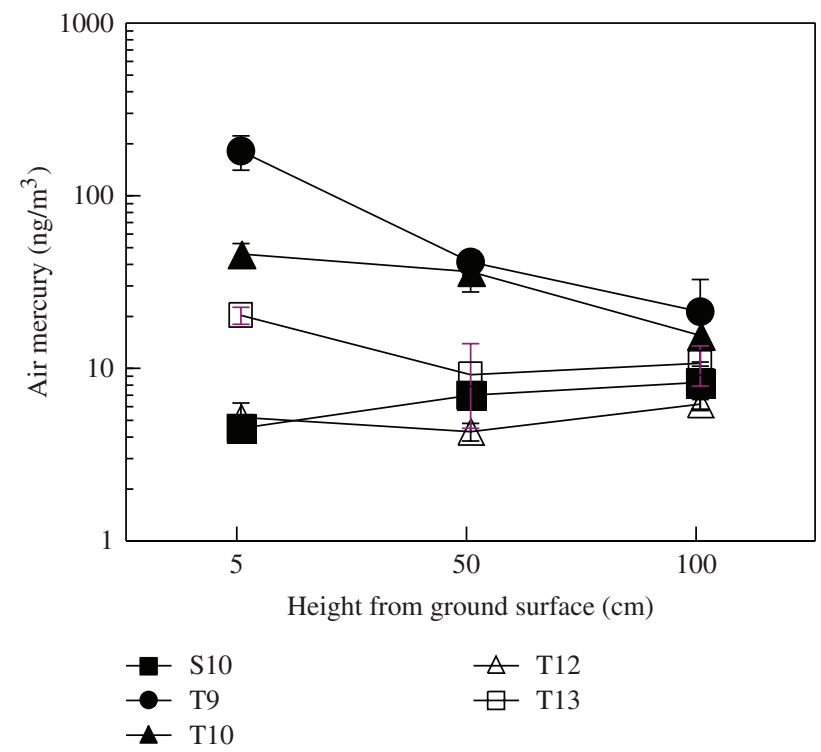

FIGURE 3: Differences in air mercury concentrations at various heights. Concentrations at 5 (without a chamber), 50, and $100 \mathrm{~cm}$ heights were measured at five points, S10, T9, T10, T12, and T13, respectively, with various mercury concentrations in surface air (see Figures 1 and 6).

\section{RESULTS AND DISCUSSION}

The air survey was conducted along profiles crossing the investigated area at $50 \mathrm{~m}$ intervals (see Figure 1). A cylindrical chamber (see Figure 2) was used for regular surface air sampling to neutralize mercury variations in the air due to the influence of "remote" mercury transfer by the wind. Prior to the survey, to examine the vertical distribution of mercury in air, we took measurements at heights of 5 (without the chamber), 50, and $100 \mathrm{~cm}$ above five sites with low, intermediate, and heavy soil pollution. Due to atmospheric turbulent diffusion, the mercury concentration at a height of $100 \mathrm{~cm}$ above the polluted points decreased to $53 \%$ of that at the ground level. In contrast, at points with a background surface level around $5 \mathrm{ng} / \mathrm{m}^{3}$, the mercury concentrations at a height of $100 \mathrm{~cm}$ were by a factor of 1.2-1.9 higher than those at the surface levels due to mercury transfer by wind from the contaminated sites (Figure 3). Thus, the air sampling close to the ground surface provides the most detailed mapping of soil contamination.

Air mercury concentrations were also measured before and after removing the surface soil to a depth of about $5 \mathrm{~cm}$ at each point. In general, after removing the surface soil, the concentration tends to rise (Figure 4). This corresponds to the known effect of the release of mercury absorbed by soil particles to the gas phase due to any mechanical action. Such a technique has been used for mercury surveys of soil 
gas at ore deposits [9]. Moreover, since 7 years had passed from the termination of factory production in Qingzhen, the "initial" surface layer of the valley had become covered by new alluvio-proluvial sediments, and some of the volatile mercury in the boundary layer could have been already vaporized or bound to soil particles. For our regular air survey, we measured the mercury concentrations immediately after surface soil removal.

The mercury concentration values obtained in the Qingzhen field varied from 4 to $598 \mathrm{ng} / \mathrm{m}^{3}$ when the surface soil was removed (Figure 5). The lowest mercury concentration in air was identical to an average value of $5.8 \pm 1.5 \mathrm{ng} / \mathrm{m}^{3}$ obtained at 5 reference points in the nonpolluted area near Lanchong Village $60 \mathrm{~km}$ to the southwest. Most of the sampling points with the high mercury levels above $50 \mathrm{ng} / \mathrm{m}^{3}$ were found along the Zhujia River, where polluted wastewater had been discharged as long ago as 1998. In general, the distribution of mercury in the surface air was similar to that in the soils reported in previous papers [2-4] and confirmed by this study. The highest concentrations exceeding $100 \mathrm{ng} / \mathrm{m}^{3}$ were found at five points, T9, U10, W10, T13, and Q16. These points were located along the river, except for W10, which was more than $100 \mathrm{~m}$ away from the river. Mercury concentration levels along the three lines including these points, that is, T8-T14, T10-X10, and Q15-Q20 (Figure 2), were measured at $10 \mathrm{~m}$ intervals (as shown in Figure 6) to determine the mercury evaporation feature in more detail. The $10 \mathrm{~m}$ measurement revealed that the distribution of mercury evaporated from the soil was quite heterogeneous, with concentration levels sometimes varying by several times between two points only $10 \mathrm{~m}$ apart. These findings indicated that mercury contaminations had sometimes occurred in a heterogeneous manner within very small areas. The farmers admitted that they sometimes used the sediments from the river as a fertilizer for the farm. Accordingly, contamination could occur due to fertilization by the sediment as well as irrigation by the river water, with the former case possibly causing the spot-contaminations observed here. Thus, mercury vapor $\mathrm{Hg}(0)$ in ambient air had originated from the polluted soil, which is evidence of ionic mercury reduction to elemental mercury.

The soil and rape samples were collected at the same points at which the air measurements were made (Figure 2). Total mercury concentrations in the soil samples ranged between 0.26 and $186 \mu \mathrm{g} / \mathrm{g}$ dry wt. and showed a distribution similar to the previous results $[3,10,11]$. The total mercury concentration levels in the rape leaf samples were in the range of $0.011-2.07 \mu \mathrm{g} / \mathrm{g}$ dry wt.

A study of the correlations of the mercury concentrations in soil, plant, and air showed their obvious dependence on distance from the chemical factory. In this regard, the investigated area can be tentatively divided into two segments along the west-to-east direction with a border at line no. 10 in Figure 1, thereby providing evidence of mercury species transformation during a mass transfer from the pollution source. In this respect, it is useful to evaluate which mercury compounds could have been initially emitted by the factory to the river water and ambient air.

In the industrial production of acetaldehyde at the Guizhou factory, metallic mercury and iron sulfates were used as catalysts to form mercury sulfate [10]. However, most of the mercury is initially released and deposited in deponent media in inorganic form, since inorganic mercury was shown to prevail in contaminated soils of the investigated areas $[3,4,10,11]$. The mercury by-products, which could be released into the environment along with wastewater, vapor, gases, and aerosols, may include $\mathrm{Hg}(0), \mathrm{HgSO}_{4}, \mathrm{Hg}_{2} \mathrm{SO}_{4}$, $\mathrm{HgSO}_{4} * 2 \mathrm{HgO}, \mathrm{HgO}, \mathrm{HgHSO}_{4}{ }^{+}, \mathrm{CH}_{3} \mathrm{Hg}^{+}$, and other species. According to Tsygankov et al. [12], the mercury consumption rates were $910-1720 \mathrm{~g}$ per ton of acetaldehyde, and a significant portion of mercury (230-940 g per ton of acetaldehyde) was supposed to be released into the environment. Most of the mercury was considered to be released with wastewater, while up to $10 \mathrm{~g}$ per ton of acetaldehyde was emitted to the atmosphere [13]. Relatively unstable mercury species, such as $\mathrm{HgHSO}_{4}{ }^{+}$and $\mathrm{HgSO}_{4}$, would be transformed to $\mathrm{Hg}(0), \mathrm{HgO}$, bi- and polysulfate complexes, as well as other compounds that are stable under existing redox conditions in the surface and ground waters, soils, and sediments [14]. Some of the elemental mercury emitted to the air with gases, vapor, and aerosols could be bonded with the surface due to wet and dry depositions near the factory. Furthermore, the photochemical dissociation of $\mathrm{HgSO}_{4}$, $\mathrm{HgSO}_{4} * 2 \mathrm{HgO}$, in aerosols and surface layers could form $\mathrm{Hg}(0)$. 


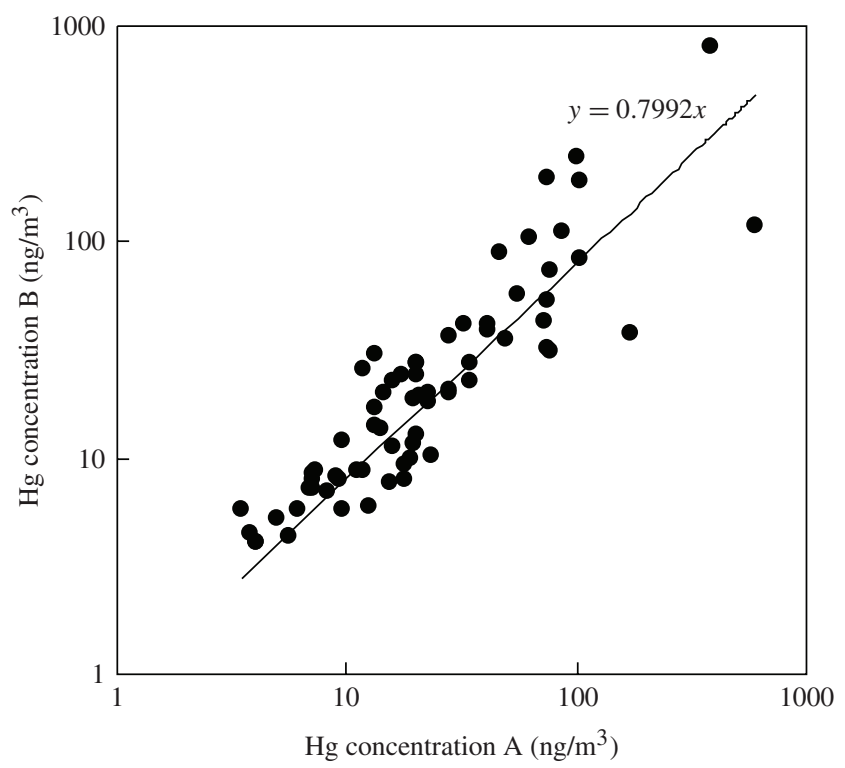

FIGURE 4: Effect of surface soil removal. Mercury concentrations in surface air at 56 sampling points were measured before and after ( $B$ and $A$ ) removing surface soil.

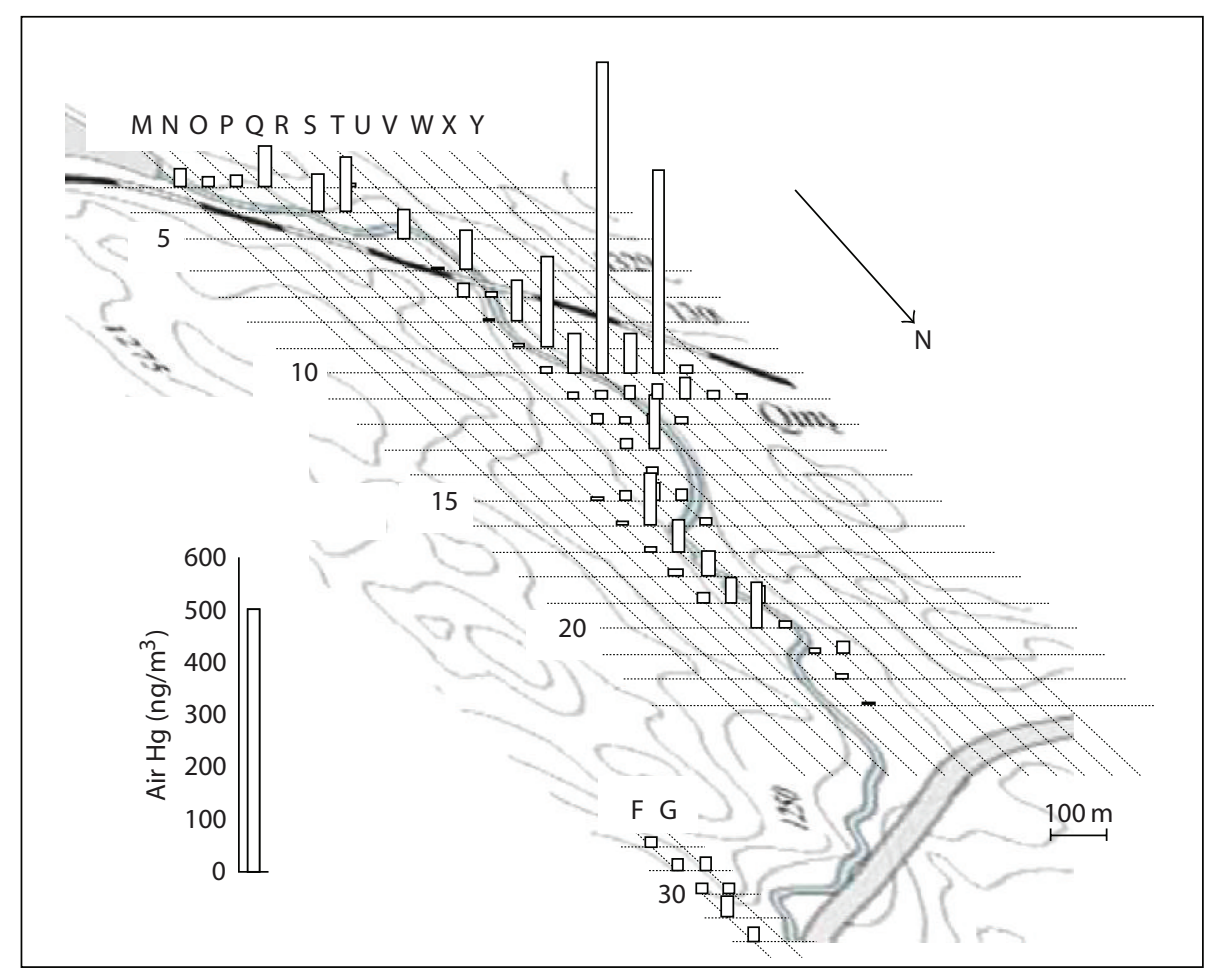

FIGURE 5: Distribution of mercury concentrations in surface air in the Qingzhen field. Ten-second measurements were repeated 6 times, and mean values for $60 \mathrm{~s}$ at each point were shown as a column. 


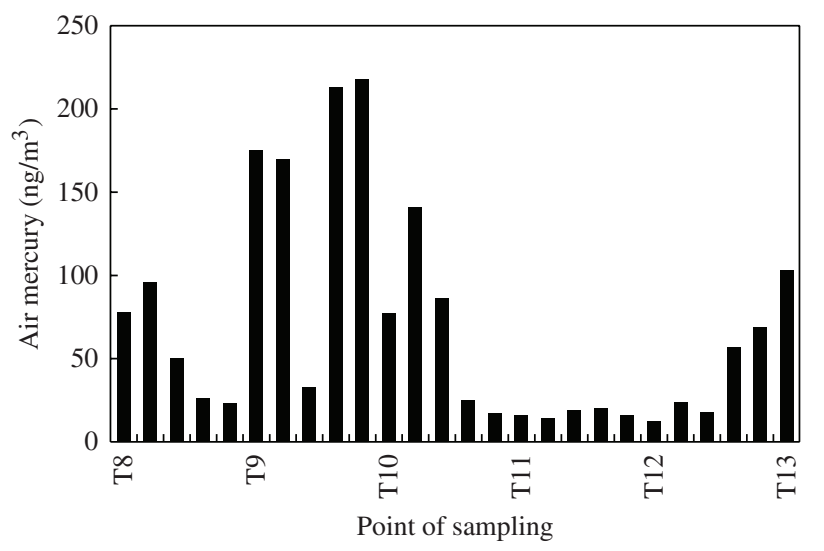

(a)

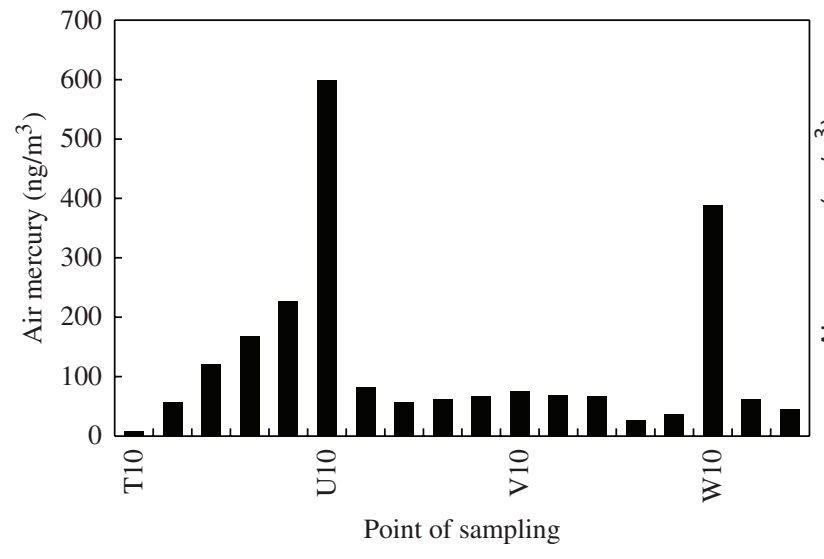

(b)

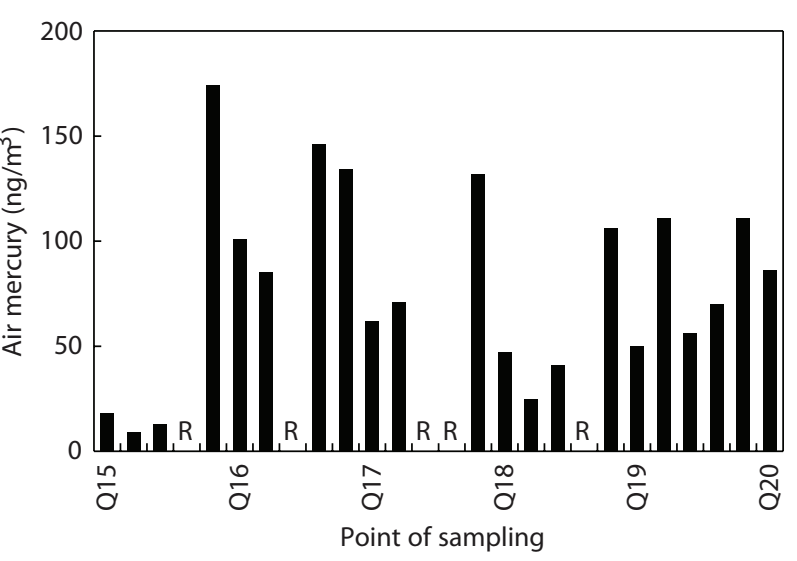

(c)

FIGURE 6: Distribution of mercury concentration in surface air along lines containing high concentrations. Mercury levels along three lines, including sites with air mercury levels above $100 \mathrm{ng} / \mathrm{m}^{3}$, (a) T8 to T14, (b) T10 to X10, and (c) Q15 to Q20, were measured at $10 \mathrm{~m}$ intervals. Sites designated "R" are located in the river.

The soil mercury concentrations showed a fair correlation with the air mercury concentration levels $(r=0.483, P<0.001)$, as can be seen in Figure 7(a). In the northern part of the surveyed area, the slope of the air-to-soil concentration ratio $\left(\mathrm{ng} / \mathrm{m}^{3}\right.$ versus $\left.\mu \mathrm{g} / \mathrm{g}\right)$ is by a factor of 2.5 smaller than that in the southern part $(0.77$ versus 1.96 , Figures 7(b) and 7(c)). This finding offers evidence that a portion of $\mathrm{Hg}(0)$ in soils could decrease with the distance from the pollution source. In the northern area, $\mathrm{Hg}(0)$ could be oxidized to $\mathrm{HgO}$ and be firmly bound to $\mathrm{Fe}$ and $\mathrm{Mn}$ oxides and hydroxides, clay minerals, and organic material.

Leaf samples of Brassica rapa were collected at 20 of 56 sampling points. The total mercury concentration levels in the leaf samples ranged from 0.011 to $2.07 \mu \mathrm{g} / \mathrm{g}$ dry wt.; their correlation with the soil levels $(r=0.454, P<0.05)$ is shown in Figure 8(a). The correlation coefficients calculated separately for the southern and northern parts of the area increased to $0.823(P<0.05)$ and $0.656(P<0.01)$, respectively, which are closer to and farther from the pollution source (Figures 8(b) and 8(c)). The slope pertaining to the southern area (0.021) was by a factor of 4.2 larger than that in the northern area (0.005). This possibly indicates that the part of relatively unstable soluble mercury species (such as $\mathrm{HgSO}_{4}$ and the like), which could be absorbed by rootage, is about 4 times as large as that in the southern area.

Mercury uptake by the plants could also occur via the stomata as a vapor, as well as through the roots as inorganic and organic mercury ions and complexes. Correlations between mercury concentrations in air and leaves showed a feature similar to that observed for soil and plants, with the plant-to-air concentration 


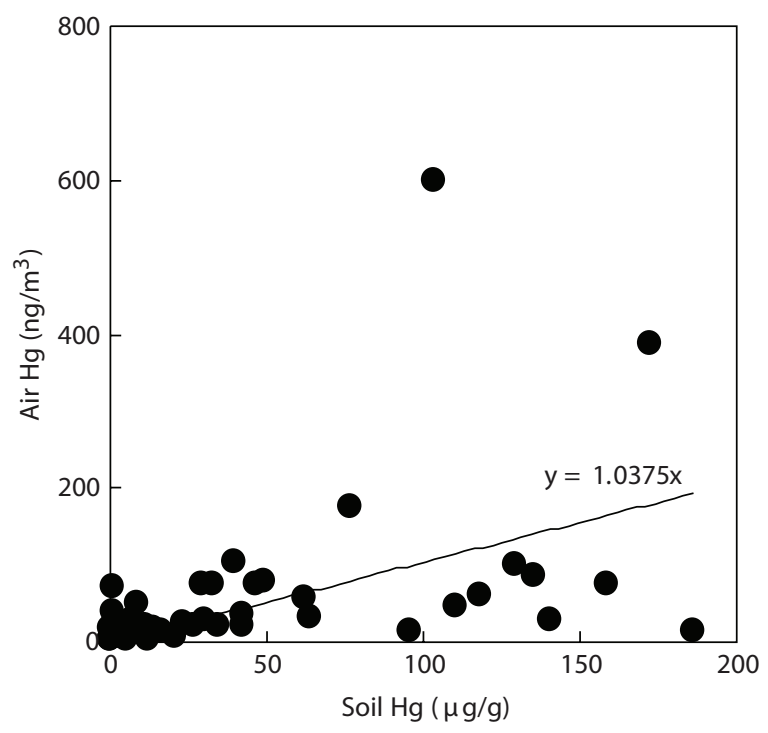

(a)

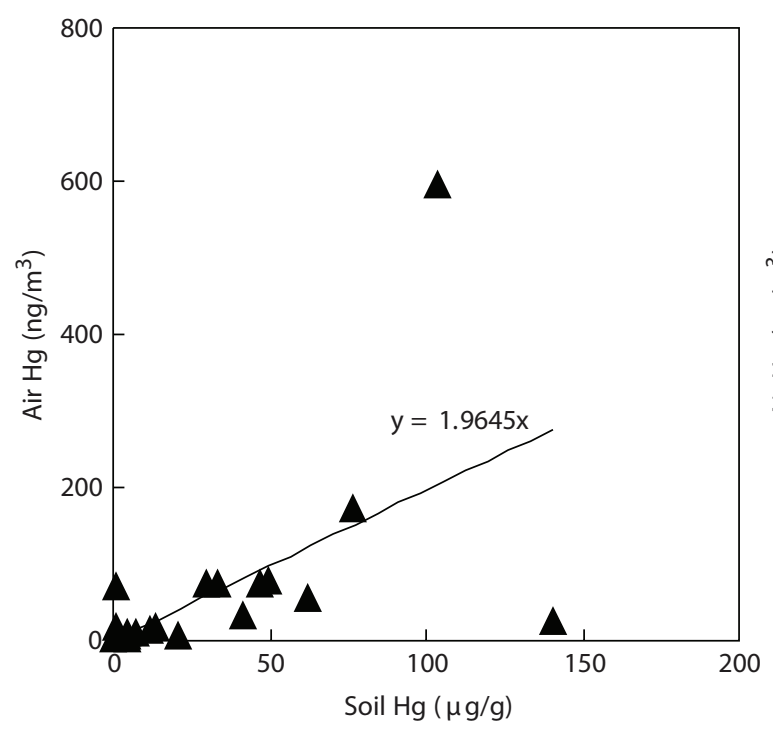

(b)

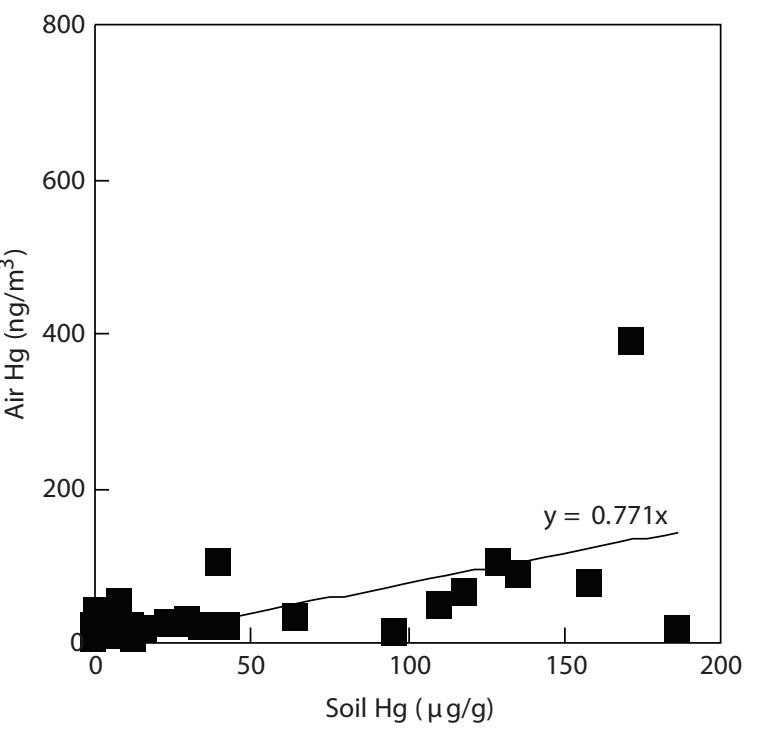

(c)

FIGURE 7: Correlation between soil and surface air mercury concentrations. Concentrations in surface air and soil samples were compared in (a) entire study area, (b) southern, and (c) northern areas.

ratio (4.25) in the southern part being higher than that in the northern part (Figures 9(a), 9(b), and 9(c)). Because Brassica rapa is an annual plant, the mercury content in leaves at time of sampling represents its accumulation during few months at most since germination. The similarity between Figures 8 and 9 suggests that the absorption from soil, rather than from air, gave rise to the major contribution to the mercury uptake by Brassica rapa in the Qingzhen field.

\section{CONCLUSION}

The technology used by the Guizhou chemical factory for acetaldehyde production led to emission into the environment of various mercury compounds, including elemental, inorganic, and organic species, which were later transformed to species that remain stable under existing physicochemical conditions. Data of 


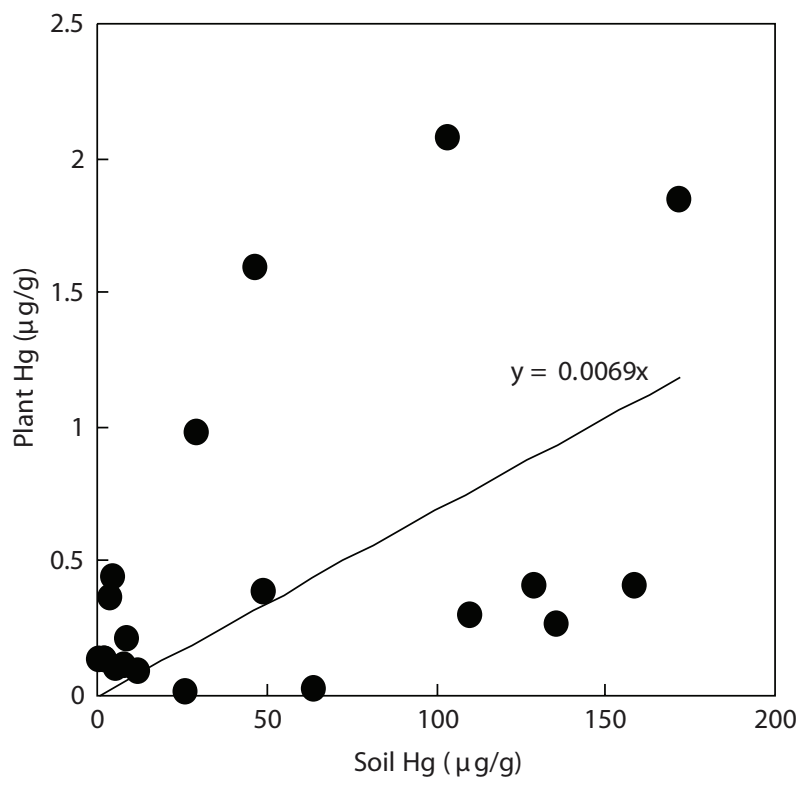

(a)

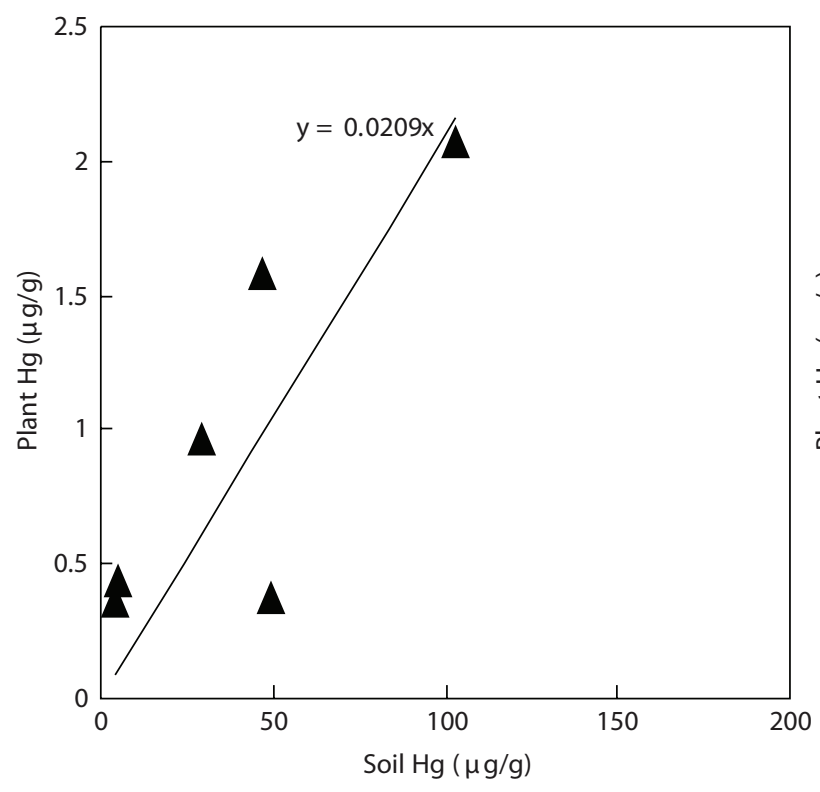

(b)

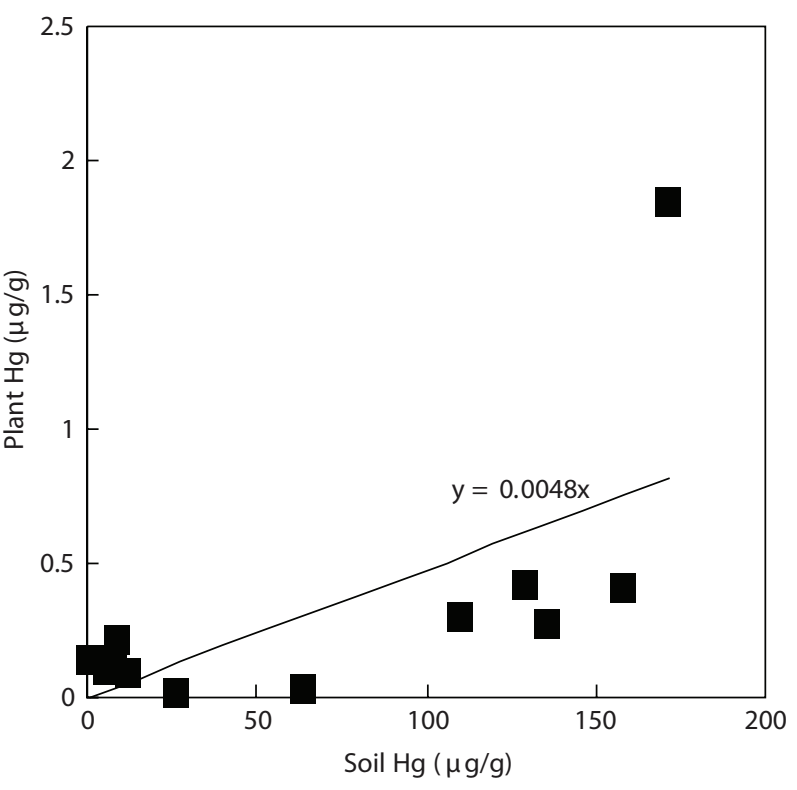

(c)

FIGURE 8: Correlation between soil and plant leaf mercury concentrations. Mercury concentrations in soil and Brassica rapa leaf samples were compared in (a) entire area, (b) southern, and (c) northern areas.

the air survey, soil and vegetation (Brassica rapa) analyses show the difference in the proportion of mobile and bound mercury species, depending on their distance from the factory. In the vicinity of the pollution source (south of the investigated Qingzhen field), a portion of $\operatorname{Hg}(0)$ and other mobile species is by a factor of 2.5 to 4.25 larger than in the "remote" northern part of the Zhujia River valley. The results obtained demonstrated that an air mercury survey using a portable mercury analyzer RA-915+ is a convenient and useful method in an advanced field survey for the rapid detection and mapping of areas affected by mercury pollution. 


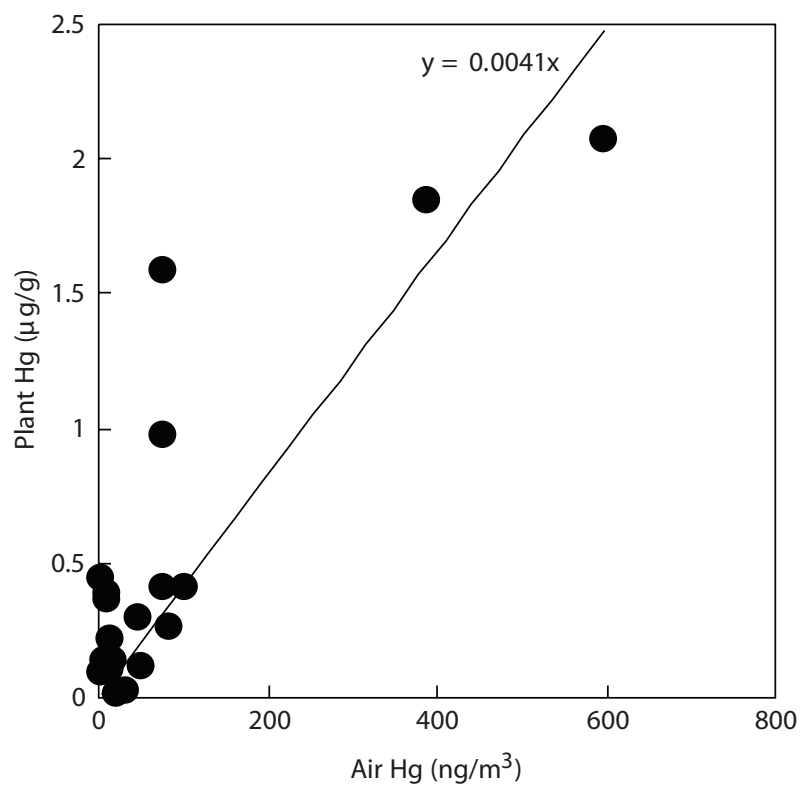

(a)

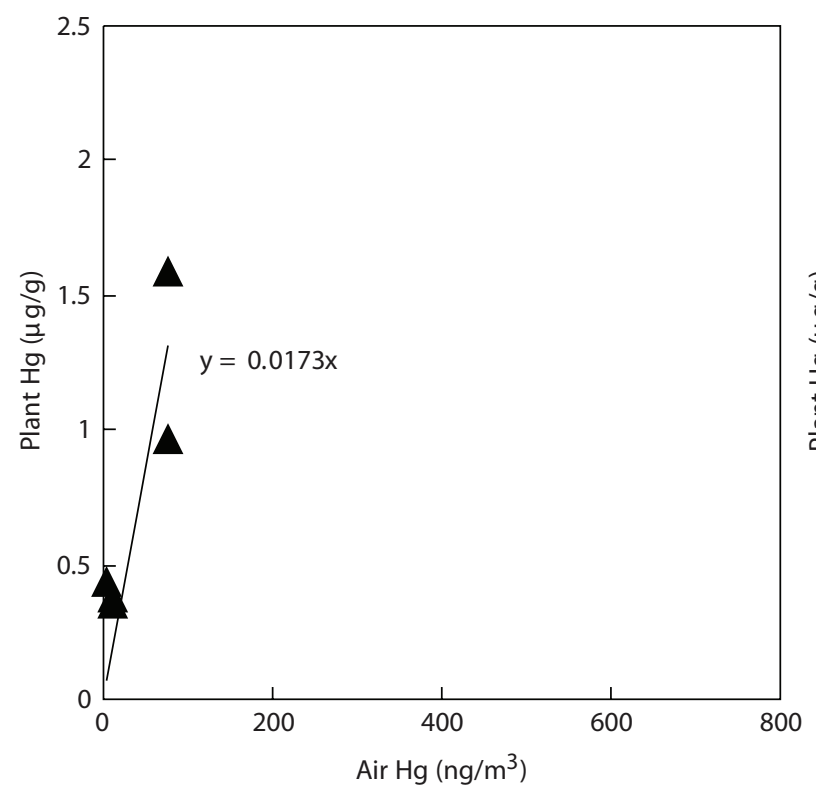

(b)

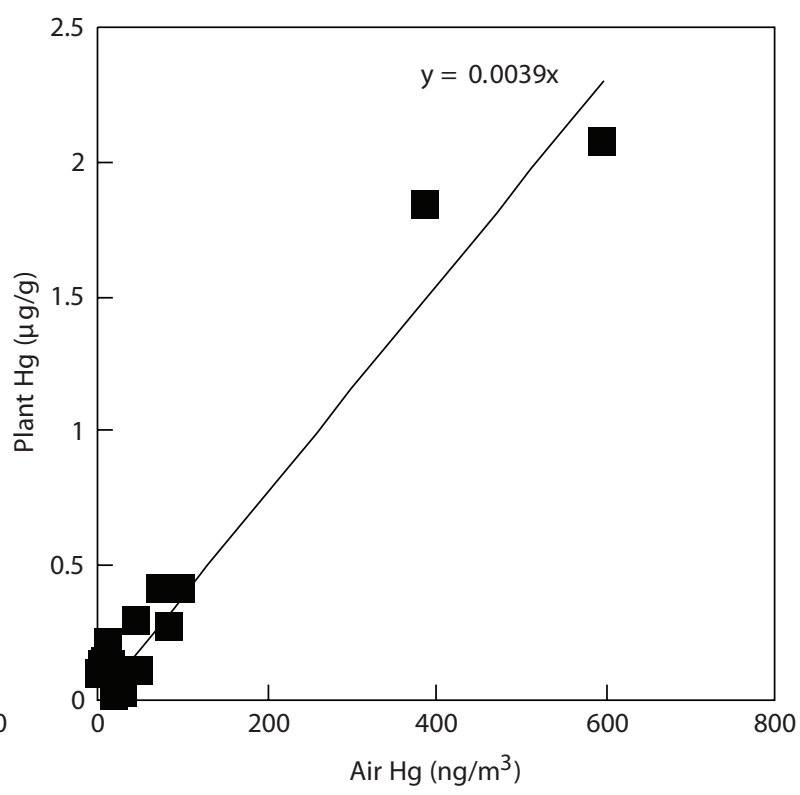

(c)

FIGURE 9: Correlation between air and plant leaf mercury concentrations. Mercury concentrations in air and Brassica rapa leaf samples were compared in (a) entire, (b) southern, and (c) northern areas.

\section{ACKNOWLEDGMENTS}

The authors are most grateful to Professor J. Murata (The University of Tokyo) and H. Murata (Setsunan University) for valuable suggestions on the preparation of botanical specimens. This work was supported in part by a Kitasato University Research Grant for Young Researchers (to M. Kiyono). 


\section{REFERENCES}

[1] H. Yan and X. Feng, "Total mercury in sediment profiles from a historical Hg-contaminated reservoir: Baihua Reservoir, Guizhou, China," in Proceedings of the 8th International Conference on Mercury as a Global Pollutant, p. 63, Madison, Wis, USA, August 2006.

[2] Y. Yasuda, A. Matsuyama, A. Yasutake et al., "Mercury distribution in farmlands downstream from an acetaldehyde producing chemical company in Qingzhen City, Guizhou, People's Republic of China," Bulletin of Environmental Contamination and Toxicology, vol. 72, no. 3, pp. 445-451, 2004.

[3] A. Matsuyama, Q. Liya, A. Yasutake et al., "Distribution of methylmercury in an area polluted by mercury containing wastewater from an organic chemical factory in China," Bulletin of Environmental Contamination and Toxicology, vol. 73, no. 5, pp. 846-852, 2004.

[4] A. Matsuyama, Y. Yasuda, A. Yasutake et al., "Detailed pollution map of an area highly contaminated by mercury containing wastewater from an organic chemical factory in People's Republic of China," Bulletin of Environmental Contamination and Toxicology, vol. 77, no. 1, pp. 82-87, 2006.

[5] A. Yasutake, A. Matsuyama, N. Mashyanov, V. Ryzhov, and A. Nikiforov, "Mercury monitoring in ambient air in Minamata area," Rudarsko-Metalurski Zbornik, vol. 51, pp. 1834-1837, 2004.

[6] S. Sholupov, S. Pogarev, V. Ryzhov, A. Stroganov, N. Mashyanov, and J. Siperstein, "Multifunctional Zeeman mercury analytical system RA-915+: practical experience and future trends," Rudarsko-Metalurski Zbornik, vol. 51, pp. 2019-2021, 2004.

[7] S. Rodrigues, M. E. Pereira, A. C. Duarte et al., "Mercury in urban soils: a comparison of local spatial variability in six European cities," Science of the Total Environment, vol. 368, no. 2-3, pp. 926-936, 2006.

[8] S. Uraguchi, I. Watanabe, A. Yoshitomi, M. Kiyono, and K. Kuno, "Characteristics of cadmium accumulation and tolerance in novel Cd-accumulating crops, Avena strigosa and Crotalaria juncea," Journal of Experimental Botany, vol. 57, no. 12, pp. 2955-2965, 2006.

[9] Y. D. Zherebtsov, M. I. Politikov, and V. Y. Sikorsky, The Technology of Mercurometric Exploration of Ore Deposits, Nedra Publishing House, Moscow, Russia, 1992.

[10] J. Zhang, "Mercury deposit distribution in the Paddy fields downstream from an organic chemical company," in Proceedings of the 8th International Conference on Mercury as a Global Pollutant, p. 62, Madison, Wis, USA, August 2006.

[11] M. Horvat, N. Nolde, V. Fajon et al., "Total mercury, methylmercury and selenium in mercury polluted areas in the province Guizhou, China," The Science of the Total Environment, vol. 304, pp. 231-256, 2003.

[12] A. P. Tsygankov, O. F. Balatskiy, and V. N. Senin, Technical Progress, Chemistry, Environment, Khimiya, Moscow, Russia, 1979.

[13] S. V. Kakareka, T. I. Kuharchik, V. S. Khomich, and E. P. Yanin, State and Problems of Inventorization of Mercury Emission to the Atmosphere. Ecological and Geochemical Problems of Mercury, IMGRE, Moscow, Russia, 2000.

[14] S. M. Ullrich, T. W. Tanton, and S. A. Abdrashitova, "Mercury in the aquatic environment: a review of factors affecting methylation," Critical Reviews in Environmental Science and Technology, vol. 31, no. 3, pp. 241-293, 2001.

\section{This article should be cited as follows:}

Akira Yasutake, Jin Ping Cheng, Masako Kiyono, Shimpei Uraguchi, Xiaojie Liu, Kyoko Miura, Yoshiaki Yasuda, and Nikolay Mashyanov, "Rapid Monitoring of Mercury in Air from an Organic Chemical Factory in China Using a Portable Mercury Analyzer," TheScientificWorldJOURNAL, vol. 11, pp. 1630-1640, 2011. 


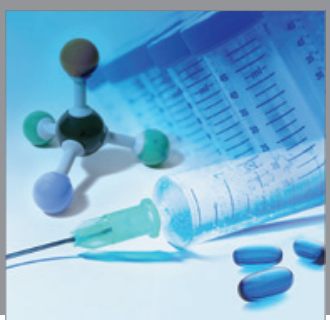

International Journal of

Medicinal Chemistry

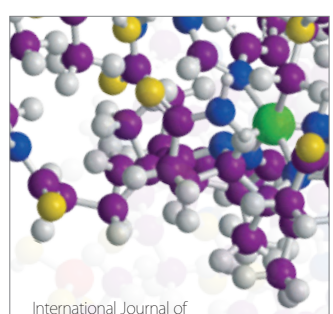

Carbohydrate Chemistry

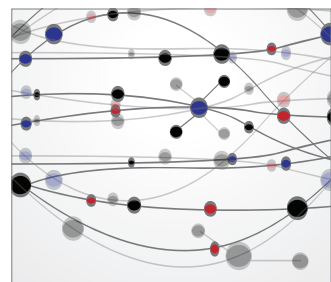

The Scientific World Journal
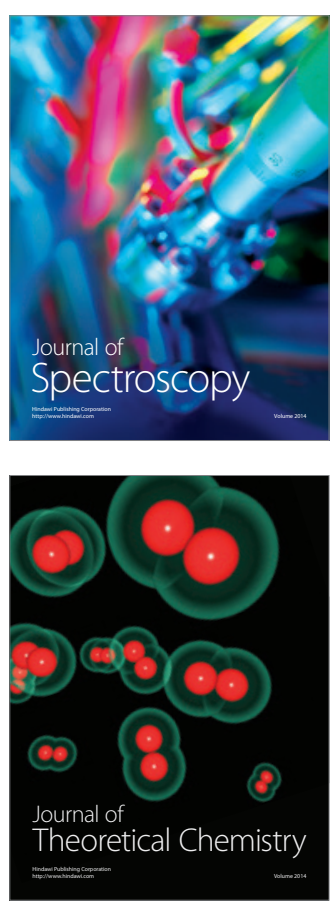
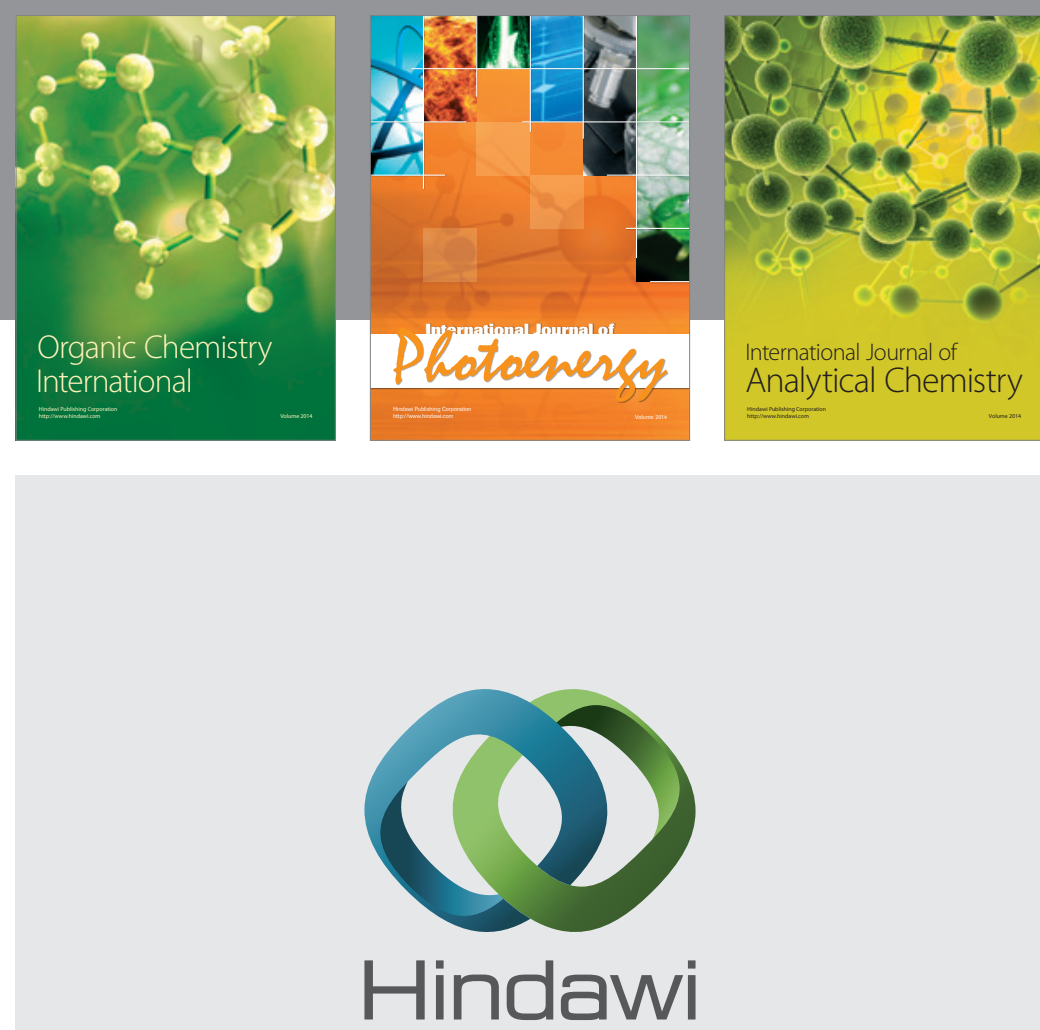

Submit your manuscripts at

http://www.hindawi.com
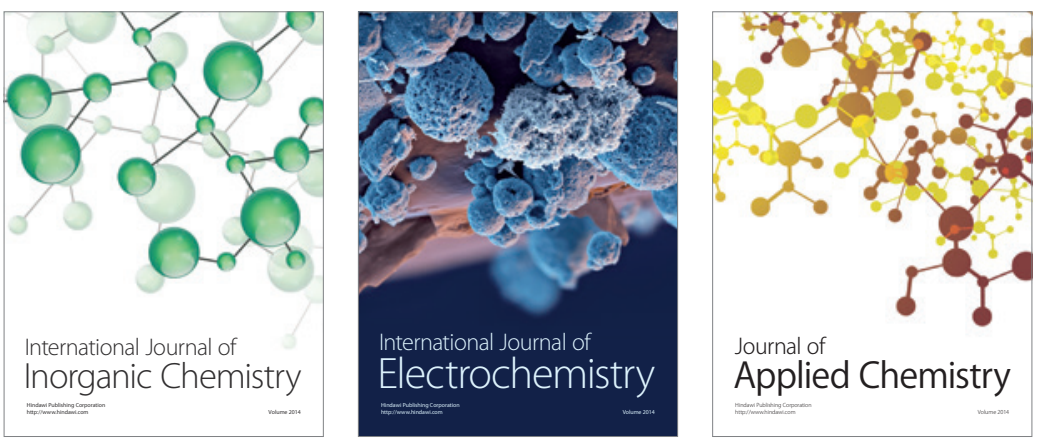

Journal of

Applied Chemistry
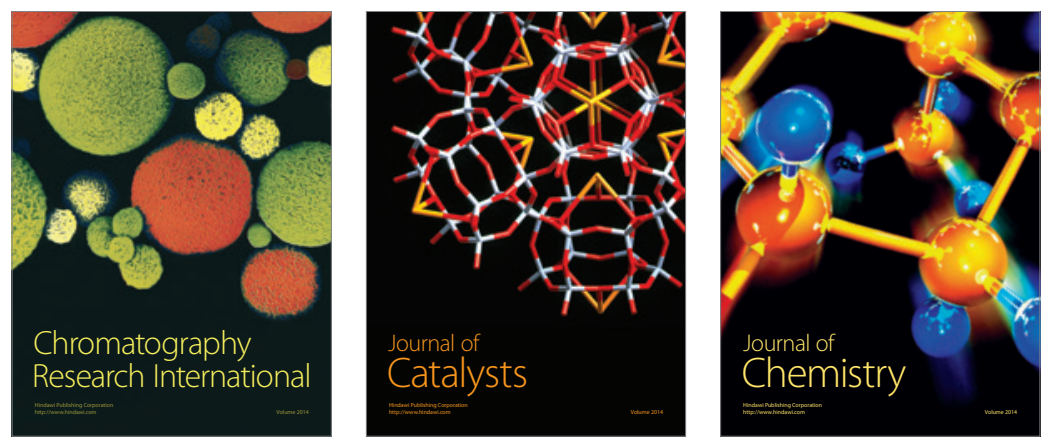
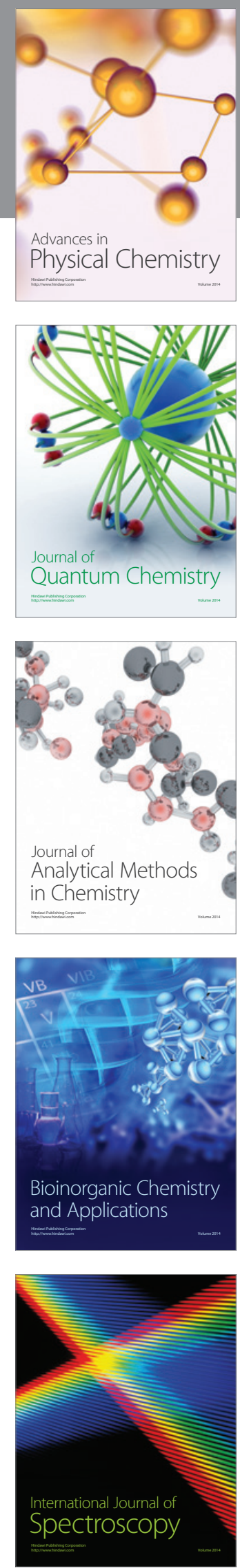